\title{
Alteration of gene expression profile following PPP2R5C knockdown may be associated with proliferation suppression and increased apoptosis of K562 cells
}

\author{
Sichu Liư ${ }^{1 \dagger}$, Qi Shen ${ }^{1,2 \dagger}$, Yu Chen ${ }^{1,3}$, Chengwu Zeng ${ }^{1}$, Changshu Cao ${ }^{1}$, Lijian Yang ${ }^{1}$, Shaohua Chen ${ }^{1}$, Xiuli Wu ${ }^{1}$, \\ Bo Li $\mathrm{Li}^{1}$ and Yangqiu Li $\mathrm{i}^{1,3^{*}}$
}

\begin{abstract}
We reported that knockdown of PPP2R5C by siRNA led to proliferation inhibition and apoptosis induction in K562 cells. In this study, we further characterized the gene expression profiles after PPP2R5C suppression by microarray analysis. Genes which participate in the MAPK, PI3K/AKT, and JAK/STAT pathways, were mainly altered in the K562 cells. We propose that the mechanism for proliferation inhibition and increased apoptosis of K562 cells following PPP2R5C suppression may be related to the alteration of expression profiles of BRAF, AKT2, AKT3, NFKB2 and STAT3 genes.
\end{abstract}

Keywords: PPP2R5C, CML, BCR-ABL, Gene expression profile

\section{Findings}

Overexpression of PPP2R5C is associated with the malignant transformation of several kinds of leukemia [1]. Recently we characterized the effects of downregulating PPP2R5C on the proliferation and apoptosis of $\mathrm{K} 562$ and Jurkat cells using different siRNAs which were targeting PPP2R5C. Significant proliferation inhibition was confirmed both in K562 and Jurkat cells, whereas apoptosis induction could only be observed in $\mathrm{K} 562$ and K562R cells $[2,3]$.

To further investigate the gene expression profile, PPP2R5C-siRNA991-treated K562 cells were collected at $48 \mathrm{~h}$ post transfection when PPP2R5C mRNA was most suppressed [2]. Gene expression profiles were determined and analyzed by Affymetrix microarrays as reported (See Additional file 1 for methods and materials) [3,4]. Overall,

\footnotetext{
* Correspondence: yangqiuli@hotmail.com

${ }^{\dagger}$ Equal contributors

${ }^{1}$ Institute of Hematology, Jinan University, Guangzhou 510632, China

${ }^{3}$ Key Laboratory for Regenerative Medicine of Ministry of Education, Jinan

University, Guangzhou 510632, China

Full list of author information is available at the end of the article
}

2,586 genes were upregulated and 2,601 genes were downregulated at least two-fold, when PPP2R5C-siRNA991 and SC-treated expression data were compared. We also found both the $\mathrm{Bcr}$ and $\mathrm{Abl}$ genes were downregulated (fold change: -1.23 and -1.53 , respectively), suggesting that PPP2R5C is closely related to the BCR-ABL-mediated pathway. Besides that, there were changes in genes involved in different signaling pathways closely related to cell proliferation and apoptosis (Table 1, Figure 1A and B).

Aberrant BCR-ABL tyrosine kinase activity plays a crucial role in the pathogenesis of CML [5,6]. Moreover, abnormal interactions between the BCR-ABL oncoprotein and other molecules lead to the disruption of the major cellular processes, including the MAPK, JAK/STAT and PI3K/AKT signaling pathway, which can result in the dysregulation of proliferation and apoptosis [7].

In the MAPK signaling pathway, 67 genes were differentially expressed including 20 upregulated and 47 downregulated genes. The significantly downregulated genes including BRAF, MAP2K2, ELK1, NFKB2, FOS, and $J U N$. Downregulated BRAF might decrease the expression 
Table 1 Cell proliferation and apoptosis genes altered after PPP2R5Cknockdown in K562 cells in microarray analysis

\begin{tabular}{|c|c|c|c|c|}
\hline $\begin{array}{l}\text { Gene } \\
\text { symbol }\end{array}$ & NCBI accession & $\begin{array}{l}\text { Fold } \\
\text { change }\end{array}$ & Description & Pathway \\
\hline BRAF & NM_004333 & -2.24 & v-raf murine sarcoma viral oncogene homolog B1 & MAPK signaling pathway \\
\hline MAP2K2 & NM_030662 & -2.39 & mitogen-activated protein kinase kinase 2 & MAPK signaling pathway \\
\hline ELK1 & NM_001114123 & -2.65 & ELK1, member of ETS oncogene family & MAPK signaling pathway \\
\hline FOS & NM_005252 & -3.12 & FBJ murine osteosarcoma viral oncogene homolog & MAPK signaling pathway \\
\hline JUN & NM_002228 & -4.88 & jun proto-oncogene & MAPK signaling pathway \\
\hline NFKB2 & $\begin{array}{l}\text { NM_001077493 } \\
\text { MAPK signaling } \\
\text { pathway/AKT } \\
\text { signaling pathway }\end{array}$ & -2.81 & $\begin{array}{l}\text { nuclear factor of kappa light polypeptide gene enhancer } \\
\text { in B-cells } 2 \text { (p49/p100) }\end{array}$ & \\
\hline AKT2 & NM_001626 & -2.72 & V-akt murine thymoma viral oncogene homolog 2 & $\begin{array}{l}\text { MAPK signaling pathway/AKT signaling } \\
\text { pathway }\end{array}$ \\
\hline AKT3 & NM_005465 & -12.47 & $\begin{array}{l}\text { v-akt murine thymoma viral oncogene homolog } 3 \text { (protein } \\
\text { kinase } B \text {, gamma) }\end{array}$ & $\begin{array}{l}\text { MAPK signaling pathway/AKT signaling } \\
\text { pathway }\end{array}$ \\
\hline CRKL & NM_005207 & -2.14 & v-crk sarcoma virus CT10 oncogene homolog (avian)-like & $\begin{array}{l}\text { MAPK signaling pathway/AKT signaling } \\
\text { pathway }\end{array}$ \\
\hline IL6ST & NM_001190981 & -2.13 & interleukin 6 signal transducer (gp130, oncostatin M receptor) & Jak-STAT signaling pathway \\
\hline STAT3 & $\begin{array}{l}\text { NM_003150 } \\
\text { Jak-STAT signaling } \\
\text { pathway }\end{array}$ & -5.08 & $\begin{array}{l}\text { signal transducer and activator of transcription } 3 \\
\text { (acute-phase response factor) }\end{array}$ & \\
\hline MDM2 & NM_002392 & 2.26 & Mdm2 p53 binding protein homolog & $\begin{array}{l}\text { AKT Signaling Pathway/p53Signaling } \\
\text { Pathway }\end{array}$ \\
\hline ATM & NM_000051 & -2.30 & ataxia telangiectasia mutated & p53Signaling Pathway \\
\hline
\end{tabular}

and phosphorylation of the downstream proteins MAP2K2, ELK1, NFKB2, FOS and JUN (Figure 1C) [8]. As a consequence, the major effects of the proliferation inhibition in PPP2R5C-siRNA991-treated $\mathrm{K} 562$ cells might be via the BRAF inhibition.

There were alterations involved in the PI3K/AKT signaling pathway including 6 upregulated and 6 downregulated genes (Figure 1D). PPP2R5C suppression predominantly resulted in $M D M 2$ upregulation and downregulation of CRKL, AKT2, AKT3, and NFKB2. PI3K activates AKT kinases and causes the phosphorylation of downstream factors that regulate the AKTmediated cellular apoptotic machinery [8,9], while downregulation of $C R K L$ weakens BCR-ABL binding to $\mathrm{PI} 3 \mathrm{~K}$, leading to reduced AKT phosphorylation. Moreover, a reduction in NFKB2 might be directly linked to the induction of apoptosis [10], and MDM2, a negative regulator of p53, might indirectly affect apoptosis [11]. Therefore, it is thought that AKT2, AKT3 and NFKB2 might be involved in apoptosis induction in $\mathrm{K} 562$ cells after PPP2R5C inhibition.

In the JAK/STAT signaling pathway, 28 genes were differentially expressed, including 16 upregulated and 12 downregulated genes (Figure 1E). The downregulated genes IL6ST and STAT3 may play important roles in cell proliferation through inhibition of the IL-6/ JAK/STAT3 pathway, and STAT3, which is a signal transducer, plays a key role in cell survival in human hematopoietic malignancies [12]. Thus, PPP2R5C suppression might have effect on the JAK/STAT pathway through STAT3 downregulation, leading to proliferation inhibition in $\mathrm{K} 562$ cells.

Because the mediation of cell proliferation, differentiation, and transformation functions of $P P P 2 R 5 C$ is based on its induction of p53 dephosphorylation at various residues $[13,14]$, a dominant alteration in p53 pathway was found for ATM, which had 2.3-fold downregulation, and $M D M 2$, which was upregulated 2.26fold. These results are similar to our previous finding in Jurkat cells in which we showed that proliferation was suppressed by PPP2R5C-siRNA. It is thought that ATM downregulation and MDM2 upregulation might lead to a decreased transcriptional activation level for p53, suggesting that the PPP $2 R 5 C$-mediated p53 function might use the same signaling pathway in different leukemia cells.

In conclusion, we characterized altered expression profile of genes related to the $\mathrm{BCR}-\mathrm{ABL}$ signaling pathway in PPP2R5C-siRNA-treated K562 cells. The mechanism of $P P P 2 R 5 C$-suppression-mediated inhibition of proliferation and increased apoptosis in $\mathrm{K} 562$ cells may be related to the MAPK, PI3K/AKT, JAK/ STAT pathways through $B R A F, A K T 2, A K T 3, N F K B 2$ and STAT3 downregulation. However, further validation of the altered genes and related proteins is needed. 


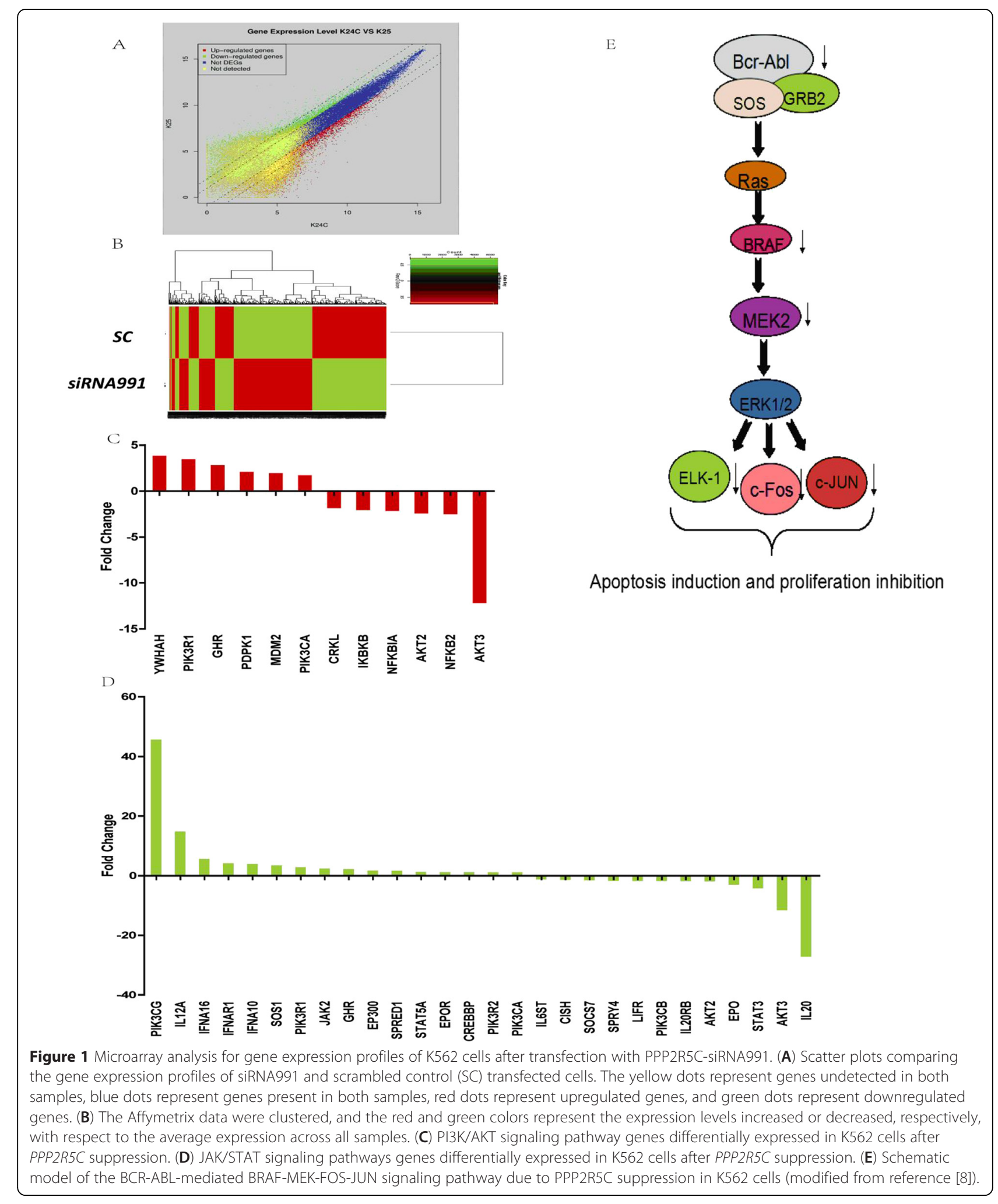




\section{Additional file}

\section{Additional file 1: Methods and materials.}

\section{Competing interests}

The authors declare that they have no competing interests.

\section{Authors' contributions}

YQL contributed to concept development and study design. SCL and QS performed the cell culture, nucleofection, and RNA isolation and data analysis. YC, CWZ, CSC, XLW and BL helped to array data analysis, LJY and SHC helped to cell culture and collect samples. YQL and SCL coordinated the study and helped draft the manuscript. All authors read and approved the final manuscript.

\section{Acknowledgements}

This study was supported by grants from National Natural Science Foundation of China (U1301226), a collaborate grant for HK-Macao-TW of the Ministry of Science and Technology (2012DFH30060), the Guangdong Science \& Technology Project (2012B050600023) and Science and Technology Innovation Key Project of Guangdong Higher Education Institutes (kjcxzd1013).

\section{Author details}

${ }^{1}$ Institute of Hematology, Jinan University, Guangzhou 510632, China. ${ }^{2}$ Department of Hematology, The Second Clinical Medical college (Shenzhen People's Hospital), Jinan University, Shenzhen 518020, China. ${ }^{3}$ Key Laboratory for Regenerative Medicine of Ministry of Education, Jinan University, Guangzhou 510632, China.

Received: 20 February 2015 Accepted: 4 March 2015 Published online: 12 April 2015

\section{References}

1. Zheng H, Chen Y, Chen S, Niu Y, Yang L, Li B, et al. Expression and distribution of PPP2R5C gene in leukemia. J Hematol Oncol. 2011;4:21.

2. Shen Q, Liu S, Chen Y, Yang L, Chen S, Wu X, et al. Proliferation inhibition and apoptosis induction of imatinib-resistant chronic myeloid leukemia cells via PPP2R5C down-regulation. J Hematol Oncol. 2013;6:64.

3. Chen Y, Liu S, Shen Q, Zha X, Zheng H, Yang L, et al. Differential gene expression profiles of PPP2R5C-siRNA-treated malignant T cells. DNA Cell Biol. 2013:32:573-81.

4. Zha X, Chen S, Yang L, Shi L, Li B, Wu X, et al. Upregulated TCRzeta enhances interleukin-2 production in T-cells from patients with CML. DNA Cell Biol. 2012;31:1628-35.

5. Sweet K, Zhang L, Pinilla-lbarz J. Biomarkers for determining the prognosis in chronic myelogenous leukemia. J Hematol Oncol. 2013;6:54.

6. Okabe S, Tauchi T, Katagiri S, Tanaka Y, Ohyashiki K. Combination of the ABL kinase inhibitor imatinib with the Janus kinase 2 inhibitor TG101348 for targeting residual BCR-ABL-positive cells. J Hematol Oncol. 2014;7:37.

7. Cilloni D, Saglio G. Molecular pathways: BCR-ABL. Clin Cancer Res. 2012;18:930-7.

8. De Luca A, Maiello MR, D'Alessio A, Pergameno M, Normanno N. The RAS/ RAF/MEK/ERK and the PI3K/AKT signalling pathways: role in cancer pathogenesis and implications for therapeutic approaches. Expert Opin Ther Targets. 2012;16 Suppl 2:S17-27.

9. Panigrahi S, Stetefeld J, Jangamreddy JR, Mandal S, Mandal SK, Los M. Modeling of molecular interaction between apoptin, BCR-Abl and CrkL-an alternative approach to conventional rational drug design. PLoS One. 2012;7:e28395.

10. Ozes ON, Mayo LD, Gustin JA, Pfeffer SR, Pfeffer LM, Donner DB. NF-kappaB activation by tumour necrosis factor requires the Akt serine-threonine kinase. Nature. 1999;401:82-5.

11. Mayo LD, Donner DB. A phosphatidylinositol 3-kinase/Akt pathway promotes translocation of Mdm2 from the cytoplasm to the nucleus. Proc Natl Acad Sci U S A. 2001;98:11598-603.

12. Sansone P, Bromberg J. Targeting the interleukin-6/Jak/stat pathway in human malignancies. J Clin Oncol. 2012;30:1005-14.

13. Shouse GP, Cai X, Liu X. Serine 15 phosphorylation of p53 directs its interaction with B56gamma and the tumor suppressor activity of B56gamma-specific protein phosphatase 2A. Mol Cell Biol. 2008;28:448-56.

14. Saha MN, Qiu L, Chang H. Targeting p53 by small molecules in hematological malignancies. J Hematol Oncol. 2013;6:23.

\section{Submit your next manuscript to BioMed Central and take full advantage of:}

- Convenient online submission

- Thorough peer review

- No space constraints or color figure charges

- Immediate publication on acceptance

- Inclusion in PubMed, CAS, Scopus and Google Scholar

- Research which is freely available for redistribution

Submit your manuscript at www.biomedcentral.com/submit
C Biomed Central 